\title{
CONTRIBUTION OF MINERALS \\ FROM FRESH KIDNEY BEAN LEAVES AND GRAINS \\ IN MEALS CONSUMED IN EAST, SOUTH AND CENTRAL AFRICA
}

\section{Mamiro $\mathbf{P M}^{1^{*}}$, Nyagaya $\mathbf{M}^{2}$, Mamiro $\mathbf{D P}^{3}$, Jumbe $\mathbf{T}^{1}$, Ntwenya $\mathrm{J}^{4}$ and $\mathrm{N}$ Bundara ${ }^{1}$}

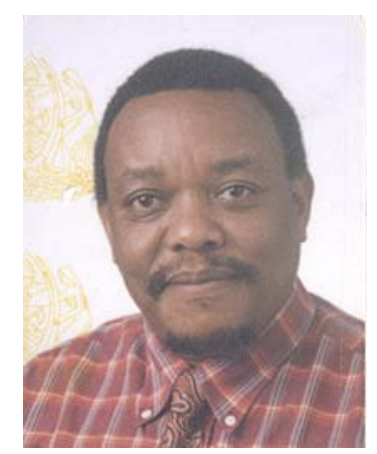

Peter Mamiro

*Corresponding author email: petermamiro@suanet.ac.tz; petermamiro@yahoo.com

${ }^{1}$ Department of Food Science and Technology, Sokoine University of Agriculture,

P. O. Box 3006, Morogoro, Tanzania

${ }^{2}$ International Centre for Tropical Agriculture, Kawanda Research Institute,

P. O. Box 6247, Uganda

${ }^{3}$ Department of Crop Science and Production, Sokoine University of Agriculture, P. O. Box 3005, Morogoro, Tanzania

${ }^{4}$ School of Nursing and Public Health, University of Dodoma, P. O. Box 259, Dodoma, Tanzania. 


\section{ABSTRACT}

Varieties of legumes are recognized as an important source of protein and dietary minerals by a number of ethnic groups in East, South and Central Africa. Among the legume that is preferred by most Africans are the bean varieties. Beans are consumed in many forms: the young leaves, green pods, and fresh bean grains are used as vegetables; dry bean grains are used in various food preparations, and both are used as relish or side dishes together with the staple food. Apart from alleviating food insecurity, the bean leaves, green bean pods and fresh bean grains are good sources of micronutrients especially iron and zinc. Thirty eight varieties of beans deemed to be rich in minerals iron and zinc collected from a number of locations in East and Central Africa were brought from University of Nairobi and multiplied at Sokoine University of Agriculture, Morogoro. Bean leaves and fresh beans grains were picked for analysis after the plants reached three weeks and two months, respectively. Iron and zinc content was determined by atomic absorption spectrophotometer after ashing the samples. Analysis showed that leaves had significantly $(\mathrm{P}<0.05)$ more iron than the fresh bean grains. For bean leaves, Maharagi soja had the highest level of iron (1653.9 mg/100g) followed by Nain De Kiondo (1061.1 mg/100g). Similarly, Maharagi soja had the highest level of zinc (40.8 mg/100g), followed by Kiangara (40.5 mg/100g). Variety HRS 545 fresh bean grains, had the highest level of iron (1114.0 mg/100g) followed by Ituri Matata (983.4 mg/100g) while highest zinc content was found in HRS 545 (41.1 mg/100g) followed by RWR 10 (41.1 mg/100g). These levels of minerals are significantly higher than the average amount found in dry bean grains (Fe 5.6 - $8.0 \mathrm{mg} / 100 \mathrm{~g}$ ) and (Zn 1.7 - $2.0 \mathrm{mg} / 100 \mathrm{~g}$ ). Creating more awareness and encouraging the utilization of bean leaves and fresh bean grains will contribute in alleviating micronutrient deficiencies especially among the vulnerable groups such as children, pregnant and lactating women, and resource-poor families.

Key words: Iron, zinc, beans leaves, fresh grains 


\section{INTRODUCTION}

A number of inorganic minerals are important either in the structure or functioning of the body and must, therefore, be provided by the various components that make up the diet [1]. Legumes, individually or as composite, are extensively used to prepare complementary and family foods in developing countries [2, 3, 4]. Common beans contain relatively high concentrations of iron (Fe) and zinc (Zn) but are also high in polyphenols and phytates, factors that may inhibit Fe and Zn absorption [5]. A study done in Nigeria showed that addition of kidney beans enhanced protein content of corn and Kocho based complementary foods from 8.8g/100 g and 1.5 g/100 g (dry weight) to $14.1 \mathrm{~g} / 100 \mathrm{~g}$ and $13.8 \mathrm{~g} / 100 \mathrm{~g}$, respectively [6].

Despite the fact that a considerable large number of crops are rich in nutrient content, still micronutrient deficiencies are high and widespread. Iron deficiency anaemia (IDA) is prevalent in many regions of the world, although South Asia and subSaharan Africa incur the most deaths [7]. Data on micronutrient deficiencies in Africa (1980 to 1990s) show very high prevalence rates of IDA especially amongst children and women [8]. In East and Central Africa, IDA prevalence rates among pregnant women are high as well. Among pregnant women studied in Ethiopia 29\% had anaemia, 13\% had iron deficiency anaemia, 33\% had depleted iron stores, and 74 and $27 \%$ had low plasma zinc and retinol, respectively [9].

Zinc deficiency was only recently recognized as a serious public health problem. It is essential for normal growth, appetite, and the immune function [10]. It is as well an essential component of more than 100 enzymes involved in digestion, metabolism and wound healing [11]. It is increasingly being recognized as critical in diets for victims of HIV/AIDS pandemic [12]. In HIV infected adults low concentrations of serum zinc have been associated with disease progression and an increased risk of death [13]. In recent analyses, zinc deficiency was found to contribute to $3.8 \%$ of the burden of disease among children aged 6 months to 5 years and to account for $14.4 \%$ of all deaths by diarrhoea, $10.4 \%$ of malaria deaths and $6.7 \%$ of pneumonia deaths in this age group [14].

Although legumes are often cited as a complement to cereals in terms of amino acid content, they also make a particular important contribution to micronutrient nutrition. For instance, decreasing legume per capita consumption in India was considered to be one possible cause of increasing iron deficiency, illustrating the importance of legumes in the diet [15]. The common bean (Phaseolus vulgaris L.) is the most important grain legume for direct human consumption, being especially important in Eastern Africa and Latin America.

Zinc content of beans is one of the highest among vegetable sources, and is nearly equal to dairy products but is far lesser than in meats. Evaluation of the bean core collection revealed a range of 21 to $54 \mathrm{ppm}$ in Zn content, with an average value of 35 ppm [15]. Germplasm from Guatemala presented especially high values of zinc, but it has not been possible to find germplasm that exceeds the levels found in the initial evaluation. 
Kidney bean leaves and fresh bean grains, which are prepared as relish and consumed by a number of families in East, Central and South African countries, stand a good chance to be disseminated to alleviate micronutrient deficiencies in developing countries. This study was undertaken to determine the levels of iron and zinc in 38 varieties of fast-tract kidney bean leaves and fresh bean grains so as to recommend them for wider multiplication and consumption.

\section{METHODOLOGY}

\section{Bean leaves and fresh bean grain samples}

Thirty eight varieties of bean samples lines deemed to contain appreciable amount of minerals especially iron and zinc were brought from University of Nairobi and multiplied at Sokoine University of Agriculture (SUA), Morogoro. These constituted a selection of the common kidney beans utilized by a number of ethnic groups in East and Central Africa. All the bean varieties were planted on a trial plot at SUA. Three to four young and tender bean leaves for each variety were picked for analysis after the plants reached about three weeks and after two months for the fresh bean grains. All analyses were done in the Food Science and Technology laboratory in collaboration with the Department of Soil Science. Mineral analysis was performed on bean leaves and fresh bean grains after dry ashing [16].

\section{Iron and zinc determination}

About $100 \mathrm{~g}$ of bean leaves and fresh bean grains for each bean variety were oven dried at $105^{\circ} \mathrm{C}$ for $24 \mathrm{hr}$. After drying $5 \mathrm{~g}$ of bean leaves and fresh bean grains were separately weighed into crucibles and dry ashed in muffle furnace maintained at $550^{\circ} \mathrm{C}$ for $2 \mathrm{hr}$. The ash was cooled in desiccators and then weighed. After weighing, the ash was dissolved in a solution of $1: 1$ ratio of $\mathrm{H}_{2} \mathrm{O}: \mathrm{HCl}$, in which the concentration of the final mixture was $6 \mathrm{NHCl}$. Total iron and zinc content of the samples was carried out by AOAC method № 968.08 and determined by atomic absorption spectrophotometer (Shimadzu UNICAM 919, England) [16]. Two replicates were analyzed for each sample.

\section{RESULTS}

Figures 1 and 2 shows the iron and zinc content in bean leaves and fresh bean grains, respectively. In general, it was observed that bean leaves had higher iron and zinc per $100 \mathrm{~g}$ dry matter than fresh bean grains. Analysis showed that leaves had significantly $(\mathrm{P}<0.05)$ more iron than the fresh bean grains. However, the levels for zinc were not significantly different.

For bean leaves, Maharagi soja had the highest level of iron (1653.9 mg/100g) followed by Nain De Kiondo (1061.1 mg/100g) while bean variety VNB 81010 had lowest iron content $(1038.1 \mathrm{mg} / 100 \mathrm{~g})$. The average iron content for all analyzed samples was $(1063.7 \mathrm{mg} / 100 \mathrm{~g})$. Similarly, Maharagi soja had the highest level of zinc (40.8 mg/100g), followed by Kiangara (40.5 mg/100g) while MLB 49-89A had 


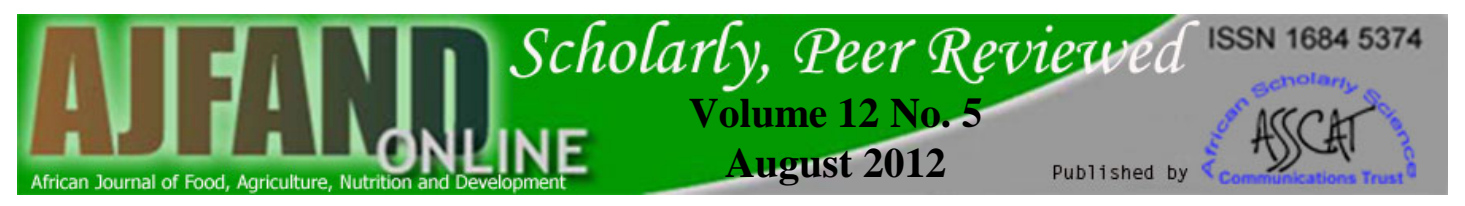

lowest zinc content $(38.2 \mathrm{mg} / 100 \mathrm{~g})$. In figure 1 , a clear separation of the concentration of iron in the bean leaves and fresh bean grains was observed.

In fresh bean grain, HRS 545 had the highest level of iron (1114.0 mg/100g) followed by Ituri Matata (983.4 mg/100g). Leaves of bean variety Kirundo had the lowest level of iron (807.3 mg/100g) while highest zinc content was found in HRS 545 (41.1 $\mathrm{mg} / 100 \mathrm{~g})$ followed by RWR 10 (41.1 mg/100g). The lowest content for zinc was found in fresh bean grain variety Awash Melka (33.2 mg/100g).

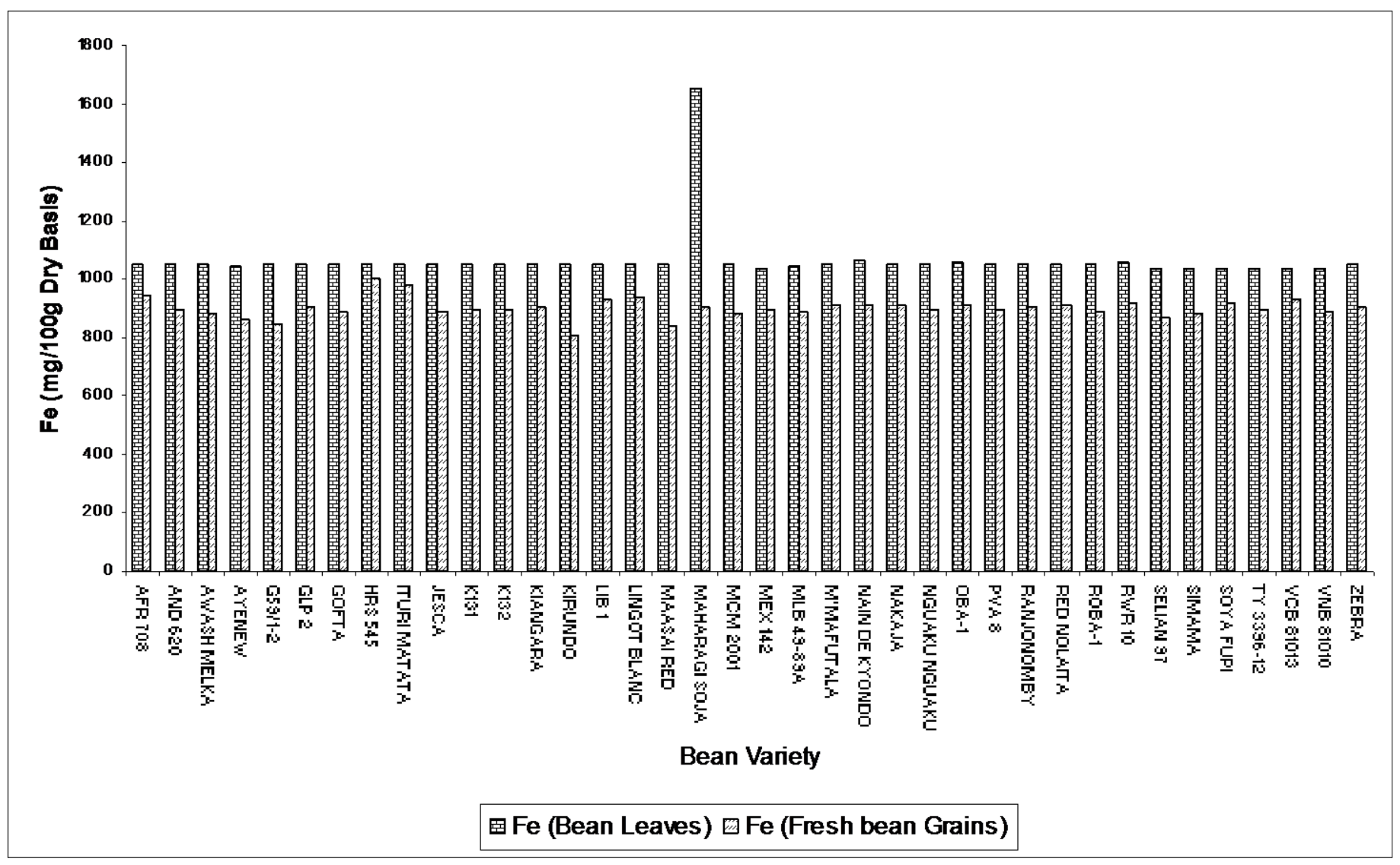

Figure 1: Iron Content in Bean Leaves and Fresh Bean Grains 

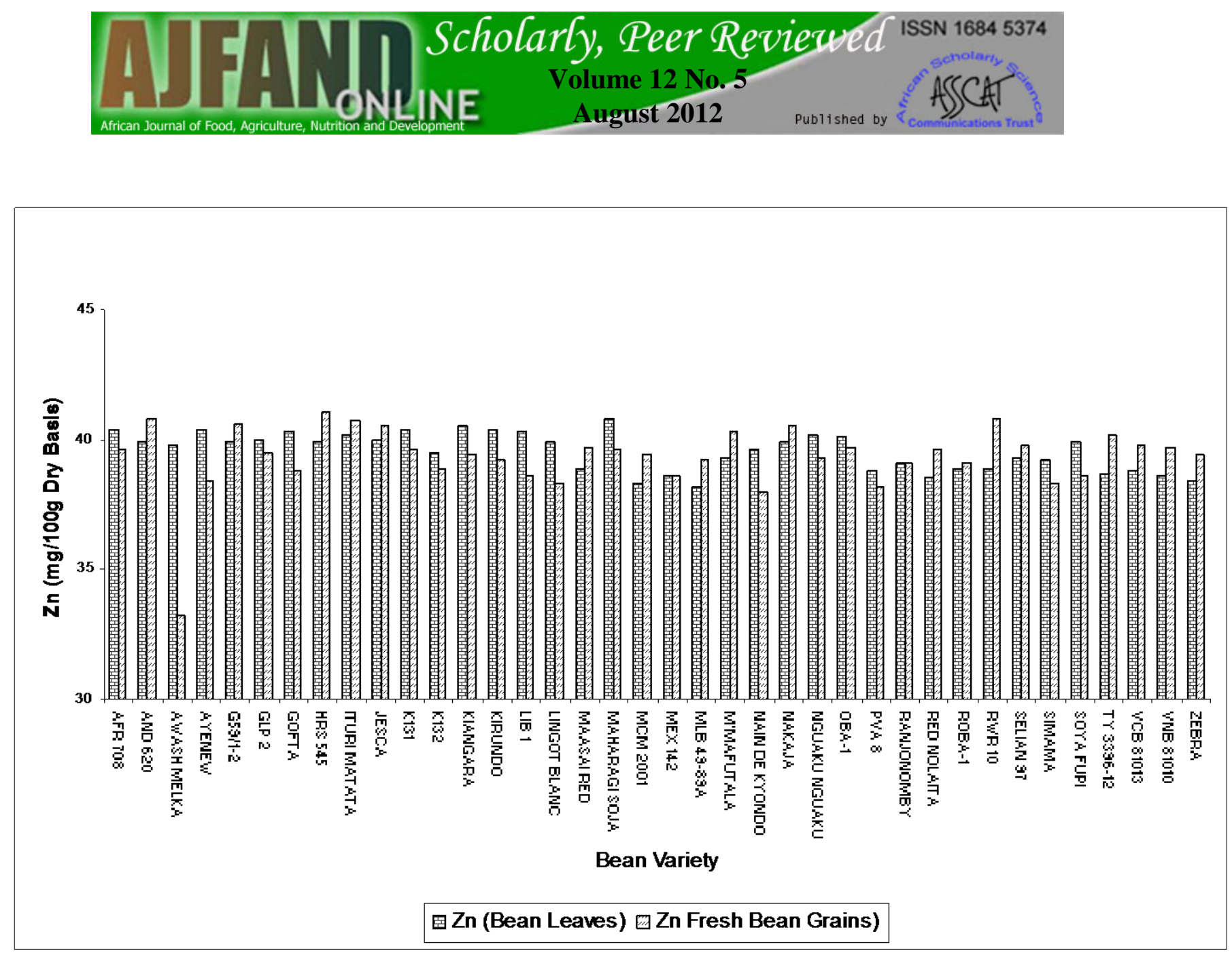

Figure 2: Zinc Content in Bean Leaves and Fresh Bean Grains 


\section{DISCUSSION}

During the past decade efforts were essentially directed towards protein and energy content of diets and improvement of energy and protein density to meet the daily requirements $[17,18]$. However, micronutrients did not receive as much attention until the 1980 to 1990's when the international community became aware of the importance of micronutrient deficiencies as a problem of public health significance all-over the world, and in particular in low income countries [18]. It is recognized by the nutrition community that micronutrient malnutrition is widespread, and is probably the most prevalent nutritional problem in the world [19]. Recently researchers have become convinced that the nutrients found in fruits and vegetables do more than just prevent deficiency diseases for instance beriberi or rickets. The most publicized finding reveals that certain vitamins or vitamin precursors in vegetables and fruits notably vitamin $C$, beta carotene and polyphenols are powerful antioxidants [20]. Antioxidants help prevent molecular damage caused by oxidation in that the protection offered may help fend-off diseases such as cancer, cardiovascular illness and muscular degeneration [21, 22]. The most vulnerable groups in these countries are infants and pregnant and lactating women, which explains the importance of examining adequate contribution of diets with regard to micronutrient requirements [23]. The bean leaves and fresh bean grains consumed by various ethnic communities in developing countries stand a good chance to be improved to alleviate micronutrient deficiencies [24]. The bean leaves and fresh bean grains are rich in calcium, iron and zinc, which are minerals of nutritional importance in African communities. Mineral analysis of the bean leaves and fresh bean grains has shown that both have comparatively higher iron and zinc content compared to dry bean grains though minor losses of minerals might have occurred due to the dry ashing method used instead of wet ashing [20].

The young bean leaves are the ones normally picked, usually the first three or four from a bean plant. For some ethnic groups, the leaves are chopped into small pieces before cooking but others just boil the whole leaves. The bean leaves and fresh bean grains seem to have a big contribution with regard to calcium, iron and zinc [25]. However, the leaves seem to have significantly more iron and zinc density compared to the fresh bean grains. Micronutrient deficiencies are widespread and have become a concern. The alleviation of these deficiencies need not be by seeking additional foods that are not commonly consumed, but instead by consuming same foods at different stages of maturation and/or different parts of the common household produced foods. Therefore, there is a great need to increase awareness especially on the vulnerable groups so that these foods are utilized for the benefit of the communities who produce them.

Findings from this study compare well with the findings in which high iron content in leaves was found in all four kidney bean cultivars at all growth stages, approximately at 9 to 12-fold higher than seed, pod, and stem [26]. The differences observed in iron content among plant organs are due to the fact that much of the iron in leaves is associated with the ferrodoxins required for photosynthesis as part of the reverse tricarboxylic acid cycle [26]. Despite the mineral density, foods originating from plant

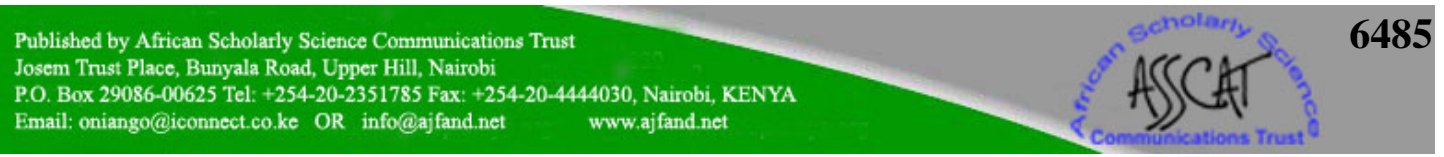




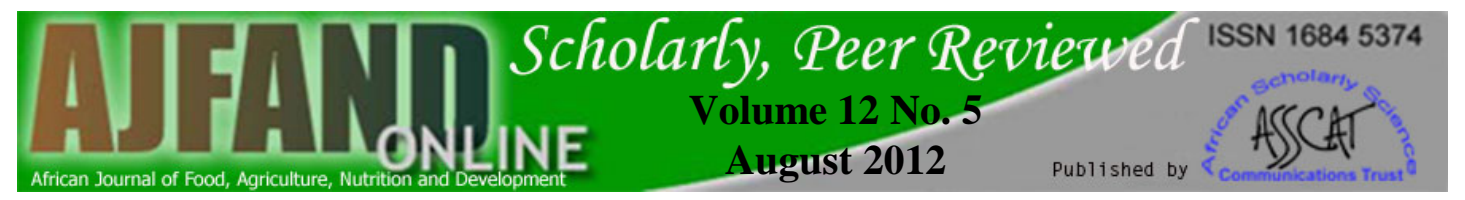

sources are more often less bio-available due to the presence among other factors of anti-nutritional factors such as phytates and tannins (27).

\section{CONCLUSION}

The iron and zinc levels in bean leaves and fresh bean grains have shown to be significantly higher than the levels in dry bean grains. Creating more awareness and encouraging the utilization of bean leaves and fresh bean grains will contribute in alleviating micronutrient deficiencies especially among the vulnerable groups such as children, pregnant and lactating women and resource-poor families.

\section{ACKNOWLEDGEMENT}

The authors would like to acknowledge the financial assistance from Association for Strengthening Agricultural Research in Eastern and Central Africa (ASARECA), PanAfrica Bean Research Alliance (PABRA) and Sokoine University of Agriculture (SUA), who facilitated laboratory analysis of bean leaves and fresh bean grains for micronutrient content. 


\section{REFERENCES}

1. Sandberg A Bioavailability of minerals in legumes. Br. J. Nutr. 2002; 88: S281- S285.

2. Uwaegbute AC Weaning practices and weaning foods of Hausas, Yorubas and Ibos of Nigeria. Ecol. Food. Nutr.1991; 26 (2): 139-153.

3. Kingamkono $\mathbf{R}$, Sjogren E, Svanberg $\mathbf{U}$ and $\mathbf{B}$ Kaijser Inhibition of different strains of enteropathogens in a lactic fermenting cereal gruel. World. J. Microb. Biot. 1995; 11: 299-303.

4. Towo $\mathbf{E}$ and $\mathbf{S}$ Tatala Iron availability in weaning foods as affected by nutrient inhibitors. Food Nutr. J. Tanzania. 1998; 9: 8-12.

5. Tako E, Glahn R P, Laparra JM, Welch RM, Lei X Kelly J D, Rutzke MA and DD Miller Iron and Zinc Bioavailabilities to Pigs from Red and White Beans (Phaseolus vulgaris L.) are Similar. J. Agric. Food Chem. 2009; 57 (8): 3134-3140.

6. Abebe $\mathbf{Y}$, Stoecker BJ, Hinds $\mathbf{M J}$ and GE Gates Nutritive value and sensory acceptability of corn and kocho based foods supplemented with legumes for infant feeding in southern Ethiopia. AJFAND. 2006; 6 (1): 1-19.

7. Mamiro PS, Kolsteren P, Roberfroid D, Tatala S, Opsomer AS and JH Van Camp Feeding Practices and Factors Contributing to Wasting, Stunting, and Iron-deficiency Anaemia among 3-23-month Old Children in Kilosa District, Rural Tanzania. J. Health, Pop. Nutr. 2005; 23 (3): 222-230.

8. Smith FI and I McGillivray A study for scientific, technical and advisory services directorate, Policy Branch. Canadian International Development Agency (CIDA), Ottawa, Canada. 2000; 32p.

9. Gibson RS, Hess SY, Hotz $\mathbf{C}$ and KH Brown Indicators of zinc status at the population level: a review of the evidence. Br. J. Nutr. 2008; 99: S14-S23.

10. Perlas LA and RS Gibson Use of soaking to enhance the bioavailability of iron and zinc from rice-based complementary foods used in the Philippines. $J$ Sci Food Agric. 2002; 82: 1115-1121.

11. Guzman-Maldonado SH, Acosta-Gallegos J and O Paredes-Lopez Protein and mineral content of a novel collection of wild and weedy common bean (Phaseolus vulgaris). J. Sci. Food. Agric. 2002; 80:1874-1881.

12. Patrick LND Nutrients and HIV: Part 2-Vitamins A and E, Zinc, B-Vitamins, and Magnesium. Altern. Med. Rev. 2000; 5(1): 39-51. 
13. Ndeezi G, Tumwine JK, Bolann J, Ndugwa $M$ and T Tylleskar Zinc status in HIV infected Ugandan children aged 1-5 years: a cross sectional baseline survey BMC Pediatrics. 2010; 10:68

http://www.biomedcentral.com/1471-2431/10/68 (Accessed: 19.10.2010).

14. Fisher WCL, Ezzati M and RE Black Global and regional child mortality and burden of disease attributable to zinc deficiency. Eur J Clin. Nutr. 2009; 63: 591-97.

15. Beebe S, Gonzalez A and J Rengifo Improving Human Nutrition Through Agriculture: The Role of International Agricultural Research. Research on Trace Minerals in Common Bean. A Workshop hosted by the International Rice Research Institute, Los Banos, Philippines organized by the International Food Policy Research Institute.1999: 1-8.

16. AOAC. Official methods of analysis. Association of Official Analytical Chemists methods, AOAC $16^{\text {th }}$ Edition. Washington, D.C. 1995.

17. Tatala S, Svanberg $\mathbf{U}$ and B Mduma Low dietary iron availability is a major cause of anaemia: a nutrition survey in Lindi District of Tanzania. Am. J. Clin. Nutr. 1998; 68: 171-173.

18. Mamiro PS Influence of complementary food on growth and iron status of infants aged 6-12 months in Kilosa District Tanzania. PhD Thesis University of Ghent, Belgium. 2003.

19. Allen HL Interventions for Micronutrient Deficiency Control in Developing Countries: Past, Present and Future. J. Nutr. 2003; 133: 3875S-3878S.

20. Oduro I, Ellis WO and D Owusu Nutritional potential of two leafy vegetables: Moringa oleifera and Ipomoea batatas leaves. Sci Res. Essays. 2008; 3 (2): 57-60.

21. Islam MZ, Lamberg AC, Bhuyan MAH and Q Salamatullah Iron status of premenopausal women in two regions of Bangladesh: prevalence of deficiency in high and low socio-economic groups. Eur J Clin Nutr. 2001; 55: 598-604.

22. Hallberg $\mathbf{L}$ and $\mathbf{L}$ Hulthen Prediction of dietary iron absorption: an algorithm for calculating absorption and bioavailability of dietary iron. Am. J. Clin. Nutr. 2000; 71: 1147-1160.

23. Gibson RS and EL Ferguson An interactive 24-hour recall for assessing the adequacy of iron and zinc intakes in developing countries. International Life Sciences Institute, Washington DC. 1999. 
24. Kingamkono R Young child feeding practices, United Republic of Tanzania. In: Complementary feeding of young children in Africa and the Middle East. Dop, M.C., Benbouzid D, Treche S, de Benoist, V and A Delpeuch (Eds). World Health Organization, Geneva. 1999: 337-342.

25. Mamiro PRS, Van Camp J, Mwikya S and M Huyghebaert In vitro extractability of calcium, iron and zinc in Finger millet and kidney beans during processing. J. Food. Sci. 2001; 66: 1271-1275.

26. Vela JA, González MG, Huerta EE, Gallegos JAA, Horacio S, Maldonado G and MAM Avilés Iron Content and Ferritin Gene Expression in Common Bean (Phaseolus Vulgaris L.) Agricultura Técnica en México. 2008; ISSN: 0568-2517; 34 (4): 481-489

http://redalyc.uaemex.mx/pdf/608/60811120011.pdf (Accessed: 23.10.2010). 